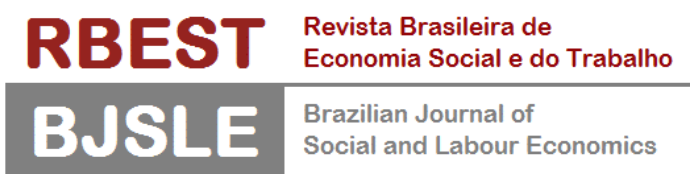

ARTIGO

\title{
Desigualdades de gênero no trabalho remunerado e no trabalho reprodutivo:
}

Uma análise para grandes regiões e estados brasileiros (2005-2015)

\author{
Luana Junqueira Dias Myrrha * \\ Silvana Nunes de Queiroz** \\ Járvis Campos***
}

\begin{abstract}
Resumo
No Brasil, os diferentes contextos econômicos, sociais, demográficos, climáticos e culturais influenciam nas desigualdades entre homens e mulheres relativas ao trabalho remunerado e ao trabalho reprodutivo (não remunerado). O objetivo deste estudo é fazer uma análise espacial (em nível regional e estadual) para verificar se houve redução dessas desigualdades entre 2005 e 2015 nos vários contextos socioeconômicos e demográficos. Os dados usados são da Pesquisa Nacional por Amostra de Domicílios (PNAD) do IBGE. As desigualdades de gênero na participação no mercado de trabalho são maiores nos estados mais pobres das regiões Norte e Nordeste. As desigualdades na remuneração média são maiores nos estados mais ricos do Sul e Sudeste, onde é maior a proporção de ocupações que exigem maior qualificação. Os diferenciais no tempo dedicado aos afazeres domésticos e ao trabalho remunerado reduziram em todos os estados, pois as mulheres diminuíram o tempo dedicado ao domicílio e aumentaram o tempo dedicado ao trabalho remunerado. Mas as desigualdades de gênero persistem elevadas, por motivos diferentes em cada contexto regional.
\end{abstract}

Palavras-chave: Desigualdades; Gênero; Trabalho; Brasil.

JEL: J16, J22, J31.

* Universidade Federal do Rio Grande do Norte (UFRN), Brasil.

Orcid: https://orcid.org/0000-0001-6767-6775

E-mail: luanamyrrha@gmail.com

* Universidade Regional do Cariri (URCA), Brasil.

Orcid: https://orcid.org/0000-0001-7295-3212

E-mail: silvana.queiroz@urca.br

** Universidade Federal do Rio Grande do Norte (UFRN), Brasil.

Orcid: https://orcid.org/0000-0002-6404-6783

E-mail: jarviscps@gmail.com

\section{$(\mathrm{Cc}) \mathrm{BY}-\mathrm{NC}-\mathrm{SA}$}

RBEST Rev. Bras. Eco. Soc. Trab. / BJSLE Braz. J. Soc. Lab. Econ., Campinas, v. 3, e021004, 2021 - ISSN 2674-9564 


\title{
Gender inequalities in paid work and reproductive work: An analysis for Brazilian macro regions and states (2005-2015)
}

\begin{abstract}
Different economic, social, demographic, climatic, and cultural contexts influence inequalities between men and women regarding paid work and reproductive (unpaid) work in Brazil. The aim of this study is to carry out a spatial analysis (at regional and state level) to verify whether there was a reduction in these inequalities between 2005 and 2015 in the various socioeconomic and demographic contexts. The data used are from IBGE's National Household Sample Survey (PNAD). Gender inequalities in labor market participation are greater in the poorest states in the North and Northeast regions. Inequalities in average remuneration are greater in the richest states in the South and Southeast, where the proportion of occupations requiring more skills is higher. The differentials in the time dedicated to housework and paid work have reduced in all the states, as women have decreased the time dedicated to home and increased the time dedicated to paid work. But gender inequalities remain high, for different reasons in each regional context.
\end{abstract}

Keywords: Inequalities; Gender; Work; Brazil.

\section{Desigualdades de género en el trabajo remunerado y el trabajo reproductivo: Un análisis para las grandes regiones y estados brasileños (2005-2015)}

\section{Resumen}

En Brasil, diferentes contextos económicos, sociales, demográficos, climáticos y culturales influyen en las desigualdades entre hombres y mujeres respecto al trabajo remunerado y al trabajo reproductivo (no remunerado). El objetivo de este estudio es realizar un análisis espacial (a nivel regional y estatal) para verificar si hubo una reducción de estas desigualdades entre 2005 y 2015 en los distintos contextos socioeconómicos y demográficos. Los datos utilizados provienen de la Encuesta Nacional de Hogares (PNAD) del IBGE. Las desigualdades de género en la participación en el mercado laboral son mayores en los estados más pobres de las regiones Norte y Nordeste. Las desigualdades en la remuneración media son mayores en los estados más ricos del Sur y el Sudeste, donde la proporción de ocupaciones que requieren más habilidades es mayor. Las diferencias en el tiempo dedicado a las tareas del hogar y al trabajo remunerado se han reducido en todos los estados, ya que las mujeres han disminuido el tiempo dedicado al hogar y han aumentado el tiempo dedicado al trabajo remunerado. Sin embargo, las desigualdades de género siguen siendo elevadas, por razones diferentes en cada contexto regional.

Palabras clave: Desigualdades; Género; Trabajo; Brasil.

\section{Inégalités de genre dans le travail rémunéré et le travail reproductif: Une analyse pour les grandes régions et États brésiliens (2005-2015)}

\section{Résumé}

Au Brésil, différents contextes économiques, sociaux, démographiques, climatiques et culturels influencent les inégalités entre hommes et femmes concernant le travail rémunéré et le travail reproductif (non rémunéré). L'objectif de cette étude est de réaliser une analyse spatiale (au niveau régional et étatique) pour vérifier s'il y a eu une réduction de ces inégalités entre 2005 et 2015 dans les divers contextes socio-économiques et démographiques. Les données utilisées proviennent de l'Enquête nationale par sondage auprès des ménages (PNAD) de I'IBGE. Les inégalités de genre dans la participation au marché du travail sont plus importantes dans les états les plus pauvres des régions du Nord et du Nord-Est. Les inégalités de rémunération moyenne sont plus importantes dans les états les plus riches du Sud et du Sud-Est, où la proportion de professions exigeant davantage de compétences est plus élevée. Les écarts de temps consacré aux tâches ménagères et au travail rémunéré se sont réduits dans tous les états, les femmes ayant diminué le temps consacré à la maison et augmenté celui consacré au travail rémunéré. Mais les inégalités entre les sexes restent élevées, pour des raisons différentes dans chaque contexte régional.

Mots clés: Inégalités; Genre; Travail; Brésil. 


\section{Introdução}

Segundo o relatório da Organização Internacional do Trabalho (OIT, 2018), as desigualdades de gênero no que se refere à participação no mercado de trabalho estão presentes na maioria dos países do mundo, com maior magnitude nos "emergentes", entre os quais o Brasil. No grupo dos países emergentes, a taxa de participação em 2018 era de 76,1\% entre os homens e apenas $45,6 \%$ entre as mulheres, ou seja, uma diferença de 30,5 pontos percentuais. Com isso, a diferença entre a taxa média de participação masculina e a taxa feminina era bem menor nos países desenvolvidos (68\% contra 52,4\%) e nos países em desenvolvimento ( $81,1 \%$ contra $69,3 \%)$.

As desigualdades de gênero também são frequentes nas diferentes regiões de cada país, principalmente por causa de desigualdades socioeconômicas, demográficas e climáticas. Países latino-americanos com elevada extensão territorial tendem a vivenciar maiores desigualdades regionais, como é o caso do México e do Brasil.

No México, de acordo com Rodríguez e García (2020), as desigualdades são evidentes em termos estaduais e municipais, e os estudos demonstram a necessidade de políticas públicas adequadas a cada contexto. No Brasil, estudos sobre a desigualdade de gênero considerando os diferentes espaços geográficos, como estados e municípios, ainda são escassos, mas urgentes, pois são significativas as desigualdades de gênero no trabalho remunerado (produtivo) e não remunerado (reprodutivo) no país como um todo (Jesus, 2018; Marri, 2009; Wajnman, 2006; Bruschini, 2007).

Assim como a maioria dos demais países do mundo, o Brasil tem o machismo e o patriarcado como elementos estruturantes dos papéis de gênero na sociedade (Saffioti, 1969/2013). A persistente divisão sexual do trabalho coloca o homem como protagonista da esfera pública, como provedor financeiro da família, e naturaliza o ambiente privado, dentro dos lares - ou seja, o trabalho doméstico e cuidado de crianças e idosos como responsabilidade feminina. A atuação do homem na esfera pública é reconhecida na medida em que o trabalho realizado é remunerado, mas também por ser considerada pela sociedade como "produtiva", merecedora de reconhecimento (V. Andrade, 2005). Por outro lado, são as mulheres que fornecem o trabalho de cuidadoras - gratuitamente - quando estão na condição esposas ou filhas (Delphy, 2013). É na instituição "família" - quando realizado por algum de seus membros, geralmente uma mulher - que esse trabalho é caracterizado como não produtivo ("reprodutivo") por não ser remunerado. Apesar de ser essencial do ponto de vista da sustentabilidade da vida humana, ninguém sai de casa para trabalhar na esfera pública sem ter usufruído do trabalho doméstico não remunerado, mas esse trabalho reprodutivo é invisibilizado e desvalorizado. 
A despeito dos avanços alcançados pelas mulheres na esfera pública, com sua significativa inserção no mercado de trabalho, a naturalização da sua responsabilidade com o cuidado da casa, crianças e idosos, restringe e molda as ocupações fora de casa, refletindo a exploração capitalista também do trabalho remunerado realizado por elas (Delphy, 2013). De acordo com a Pesquisa Nacional por Amostra de Domicílios (PNAD) do Instituto Brasileiro de Geografia e Estatística (IBGE), de 1995 para 2015, o rendimento das mulheres em relação aos dos homens passou de $70 \%$ para $74,6 \%$, ou seja, a redução da defasagem foi de apenas 4,5 pontos percentuais no período de 20 anos. Essa desigualdade, que vem se reduzindo lentamente, é consequência da segregação ocupacional por gênero, pois parte significativa das mulheres assume trabalhos mais precários, geralmente ligados à prestação de serviços (atenção à saúde, assistência, alimentação e trabalho doméstico remunerado), os quais têm baixa remuneração e/ou são informais (Oliveira, 2003). Consequência também da menor remuneração das mulheres em várias ocupações, principalmente nas mais qualificadas.

Além da diferença salarial no trabalho remunerado, também é importante destacar que as mulheres não apresentam a mesma participação no mercado de trabalho que os homens. De acordo com a PNAD, apenas 40,9\% das mulheres com mais de 10 anos estavam trabalhando em 2014, ao passo que 57,5\% dos homens estavam ocupados.

Com relação ao trabalho não remunerado dentro dos domicílios, de acordo com o IBGE, em 2015, 91\% das mulheres se dedicavam aos afazeres domésticos, ao passo que apenas $55 \%$ dos homens os faziam. Consequentemente, parcela delas permaneciam fora do mercado de trabalho para a realização desses cuidados, ao passo que as inseridas assumem a sobrecarga da dupla jornada (Neves \& Pedrosa, 2007; Dedecca, 2008).

Ainda segundo o IBGE, entre 2004 e 2014, o tempo de dedicação da mulher que trabalha fora de casa aos afazeres domésticos passou de 22,3 horas para 20,5 horas semanais, ao passo que para os homens se manteve em 10 horas semanais. Portanto, apesar das mudanças demográficas - como a queda da fecundidade e o aumento da longevidade que geram novos arranjos familiares, com a presença de poucos filhos ou sem filhos, com idosos, ou idosos que moram sozinhos -, o tempo dedicado pelas mulheres aos cuidados com a casa e a família reduziu apenas 1,8 horas em 10 anos e corresponde, em média, ao dobro do tempo médio dedicado pelos homens. Embora a desigualdade de gênero no tempo gasto com o trabalho reprodutivo venha diminuindo, tal fenômeno ocorre não pela maior contribuição dos homens, mas pela redução no tempo dedicado por elas.

A redução da desigualdade de gênero, apesar de lenta, é um fenômeno presente em todo o país. Contudo, sendo o Brasil marcado por diversas desigualdades regionais, a pergunta que permanece é: a redução da desigualdade de gênero no trabalho remunerado e no trabalho reprodutivo ocorre no mesmo ritmo em todas as Unidades Federativas? 
Portanto, o objetivo principal do presente artigo é analisar - desde uma perspectiva espacial - a redução das desigualdades de gênero no trabalho remunerado e no trabalho reprodutivo entre 2005 e 2015, no Brasil, considerando os contextos socioeconômicos e demográficos das 27 Unidades da Federação. Os dados utilizados são oriundos da Pesquisa Nacional por Amostra de Domicílios (PNAD), realizada pelo Instituto Brasileiro de Geografia e Estatística (IBGE). São analisados indicadores de desigualdade de gênero referentes a quatro tópicos: participação no mercado de trabalho e na realização de afazeres domésticos; tempo dedicado a cada tipo de trabalho (produtivo e reprodutivo); tempo total gasto (trabalho remunerado + não remunerado); e rendimento médio.

\section{Material e métodos}

A PNAD é uma pesquisa amostral dos domicílios brasileiros (realizada anualmente até 2015), ${ }^{1}$ cuja finalidade é produzir informações quanto às características socioeconômicas, ocupacionais e demográficas da população, com uma gama de perguntas sobre trabalho. As informações coletadas representam o Brasil, os 27 estados e 9 Regiões Metropolitanas.

Neste estudo, as variáveis utilizadas referem-se aos brasileiros em idade ativa, com mais de 14 anos e menos de 65 anos de idade, focando sua participação no mercado de trabalho e nos afazeres domésticos, bem como o tempo dedicado em ambas as esferas. Além disso, também são analisados os rendimentos advindos dos trabalhos remunerados.

Para analisar a participação no mercado de trabalho, primeiro é necessário delimitar o "trabalho remunerado" a partir dos seguintes quesitos:

\begin{tabular}{|l|}
\hline \multicolumn{1}{|c|}{ Quadro 1 - Trabalho remunerado } \\
\hline "Exerceu algum trabalho na semana de referência?" \\
\hline "Número de horas trabalhadas por semana no trabalho principal da semana de referência" \\
\hline "Número de horas trabalhadas por semana nesse trabalho secundário" \\
\hline "Número de horas trabalhadas por semana nesse(s) outro(s) trabalho(s) da semana de referência" \\
\hline "Rendimento mensal de todos os trabalhos para pessoas de 10 anos ou mais de idade" \\
\hline
\end{tabular}

Considerando as informações dessas variáveis, os seguintes indicadores foram construídos:

${ }^{1}$ Em 2012, foi criada a PNAD Contínua, com maior abrangência amostral e resultados trimestrais. 


\begin{tabular}{|l|l|}
\hline \multicolumn{2}{|c|}{ Quadro 2 - Indicadores de desigualdade de gênero no trabalho remunerado } \\
\hline \multicolumn{1}{|c|}{ Indicador } & \multicolumn{1}{c|}{ Cálculo } \\
\hline $\begin{array}{l}\text { Razão da participação no mercado de trabalho } \\
\text { (mulheres em relação aos homens) }\end{array}$ & $\begin{array}{l}\text { Corresponde à razão entre o percentual de mulheres } \\
\text { ocupadas na semana de referência e o percentual de } \\
\text { homens ocupados na semana de referência. }\end{array}$ \\
\hline $\begin{array}{l}\text { Razão da média salarial } \\
\text { (mulheres em relação aos homens) }\end{array}$ & $\begin{array}{l}\text { Corresponde ao rendimento médio por hora das mulheres } \\
\text { em relação ao rendimento médio por hora dos homens. }\end{array}$ \\
\hline $\begin{array}{l}\text { Razão do tempo dedicado ao trabalho remunerado } \\
\text { (mulheres em relação aos homens) }\end{array}$ & $\begin{array}{l}\text { Corresponde à razão do número de horas trabalhadas na } \\
\text { semana (no trabalho remunerado) das mulheres em relação } \\
\text { ao número de horas trabalhadas dos homens. }\end{array}$ \\
\hline
\end{tabular}

A PNAD também investiga o número de horas dedicadas aos afazeres domésticos, sem detalhamento quanto ao tempo dedicado a cada uma das atividades. São apenas duas perguntas:

\begin{tabular}{|c|}
\hline Quadro 3 - Horas dedicadas aos afazeres domésticos \\
\hline "Cuidava dos afazeres domésticos na semana de referência?" \\
\hline "Número de horas que dedicava normalmente por semana aos afazeres domésticos?" \\
\hline
\end{tabular}

A PNAD considera como atividades relacionadas aos afazeres domésticos as seguintes tarefas: arrumar ou limpar toda ou parte da moradia; cozinhar ou preparar alimentos; passar roupa, lavar roupa ou louça, utilizando, ou não, aparelhos eletrodomésticos para executar estas tarefas para si ou para outro(s) morador(es); orientar ou dirigir trabalhadores domésticos na execução das tarefas domésticas; cuidar de filhos ou menores moradores; limpar o quintal ou terreno que circunda a residência.

Contudo, é importante reconhecer que apenas essas informações não são capazes de captar com maior detalhe o uso do tempo dos brasileiros em atividades do dia a dia. Além disso, as informações declaradas pelos entrevistados sobre o tempo gasto com afazeres domésticos podem estar subenumeradas, exatamente pela ausência de um questionário mais detalhado que permita validar melhor o total do tempo dedicado a cada atividade doméstica (Jesus, 2018). Apesar dessa limitação, optou-se por utilizar a variável "tempo dedicado aos afazeres domésticos" na composição dos indicadores referentes às desigualdades de gênero no trabalho reprodutivo. 


\begin{tabular}{|c|l|}
\hline \multicolumn{2}{|c|}{ Quadro 4 - Indicadores de desigualdade de gênero no trabalho reprodutivo } \\
\hline \multicolumn{1}{|c|}{ Indicador } & \multicolumn{1}{c|}{ Cálculo } \\
\hline Desigualdade de participação no trabalho reprodutivo & $\begin{array}{l}\text { Corresponde à razão entre o percentual de mulheres } \\
\text { que realizaram trabalho doméstico na semana de } \\
\text { referência e o percentual de homens que realizaram } \\
\text { trabalho doméstico na semana de referência. }\end{array}$ \\
\hline Desigualdade no tempo dedicado ao trabalho reprodutivo & $\begin{array}{l}\text { Corresponde à razão do tempo médio dedicado aos } \\
\text { afazeres domésticos pelas mulheres em relação ao } \\
\text { tempo médio dos homens. }\end{array}$ \\
\hline
\end{tabular}

Para analisar em conjunto as desigualdades no trabalho remunerado e no trabalho reprodutivo utilizou-se a razão do tempo total gasto pelas mulheres, em média, com o trabalho nas duas esferas (mercado de trabalho e domicílio) em relação ao tempo gasto pelos homens. Por meio desse indicador foi possível avaliar os diferenciais de gênero considerando a dupla jornada dos homens e das mulheres.

Assim, todos os indicadores com resultados superiores à unidade $(>1,0)$ indicam maior participação, maior tempo ou maior remuneração das mulheres em relação aos homens. Inversamente, resultados menores que a unidade $(<1,0)$ indicam que os homens assumem a superioridade na variável que compõe o indicador.

O conjunto de indicadores foi incorporado ao Sistema de Informações Geográficas QGIS para a elaboração de mapas coropléticos, com o objetivo de analisar os resultados numa perspectiva têmporo-espacial. A distribuição dos dados foi analisada por meio de histogramas para a definição dos intervalos de classe dos mapas (representados nas legendas) para uma adequada representação dos mapas temáticos e análise comparativa entre as Unidades da Federação do Brasil.

\section{Retrato demográfico e econômico das Unidades da Federação em estudo: breve apontamento}

O Brasil é um país de dimensões continentais, seja devido a sua extensão territorial (8.516.000 km²), ou contingente populacional (190.755.799 milhões de habitantes em 2010), distribuídos por 5 grandes regiões e 27 Unidades da Federação, incluindo o Distrito Federal (Tabela 1). Entretanto, o país é historicamente marcado por elevada heterogeneidade, o que implica em diferentes 'Brasis': um moderno e desenvolvido, outro atrasado ou em processo de desenvolvimento - traços de sua ocupação e, principalmente, da falta de planejamento 
regional para equalizar os desequilíbrios regionais e estaduais (Cano \& Guimarães Neto, 1986; Araújo, 2009), conforme mostram os dados da Tabela 1.

Tabela 1. População total, percentual de pobres, percentual de mães chefes de família, taxa de fecundidade total e Índice de Desenvolvimento Humano Municipal. Brasil: grandes regiões e Unidades da Federação, 2010.

\begin{tabular}{|c|c|c|c|c|c|}
\hline $\begin{array}{c}\text { UF e } \\
\text { grande região }\end{array}$ & $\begin{array}{l}\text { População } \\
\text { total }\end{array}$ & $\begin{array}{c}\text { Pobres } \\
(\%)\end{array}$ & $\begin{array}{l}\text { Mães chefes de família } \\
\text { em condição vulnerável } \\
\text { (1) }\end{array}$ & $\begin{array}{c}\text { Taxa de } \\
\text { fecundidade total } \\
\text { (2) }\end{array}$ & IDHM \\
\hline Acre & 733.559 & 29,5 & 28,7 & 3,0 & 0.663 (médio) \\
\hline Amapá & 669.526 & 24,1 & 27,4 & 2,6 & 0.708 (alto) \\
\hline Amazonas & 3.483 .985 & 30,8 & 25,8 & 2,6 & 0.674 (médio) \\
\hline Pará & 7.581 .051 & 32,3 & 23,9 & 2,5 & 0.646 (médio) \\
\hline Rondônia & 1.562 .409 & 14,8 & 17,7 & 2,2 & 0.690 (médio) \\
\hline Roraima & 450.479 & 26,7 & 22,8 & 2,4 & 0.707 (alto) \\
\hline Tocantins & 1.383 .445 & 22,2 & 17,9 & 2,4 & 0.699 (médio) \\
\hline Norte & 15.864 .454 & 25,7 & 23,5 & 2,5 & 0.684 (médio) \\
\hline Alagoas & 3.120 .494 & 34,3 & 26,5 & 2,2 & 0.631 (médio) \\
\hline Bahia & 14.016 .906 & 28,7 & 21,8 & 2,1 & 0.660 (médio) \\
\hline Ceará & 8.452 .381 & 30,3 & 22 & 2,0 & 0.682 (médio) \\
\hline Maranhão & 6.574 .789 & 39,5 & 26,9 & 2,6 & 0.639 (médio) \\
\hline Paraíba & 3.766 .528 & 28,9 & 20,8 & 2,0 & 0.658 (médio) \\
\hline Pernambuco & 8.796 .448 & 27,2 & 22,2 & 1,9 & 0.673 (médio) \\
\hline Piauí & 3.118 .360 & 34,1 & 20,8 & 2,0 & 0.646 (médio) \\
\hline Rio Grande do Norte & 3.168 .027 & 23,8 & 17,7 & 2,0 & 0.684 (médio) \\
\hline Sergipe & 2.068.017 & 27,9 & 26,5 & 2,0 & 0.665 (médio) \\
\hline Nordeste & 53.081 .950 & 30,5 & 22,8 & 2,1 & 0.660 (médio) \\
\hline Espírito Santo & 3.514 .952 & 9,5 & 14,4 & 1,8 & 0.740 (alto) \\
\hline Minas Gerais & 19.597 .330 & 11 & 14,9 & 1,8 & 0.731 (alto) \\
\hline Rio de Janeiro & 15.989 .929 & 7,2 & 14,2 & 1,7 & 0.761 (alto) \\
\hline São Paulo & 41.262 .199 & 4,7 & 13,2 & 1,7 & 0.783 (alto) \\
\hline Sudeste & 80.364 .410 & 8,1 & 14,2 & 1,7 & 0.754 (alto) \\
\hline Paraná & 10.444 .526 & 6,5 & 14,5 & 1,9 & 0.749 (alto) \\
\hline Rio Grande do Sul & 10.693 .929 & 6,4 & 15,8 & 1,8 & 0.746 (alto) \\
\hline Santa Catarina & 6.248 .436 & 3,7 & 14 & 1,7 & 0.774 (alto) \\
\hline Sul & 27.386 .891 & 5,5 & 14,7 & 1,8 & 0.756 (alto) \\
\hline Distrito Federal & 2.570 .160 & 4,9 & 14,7 & 1,8 & 0.824 (muito alto) \\
\hline Goiás & 6.003 .788 & 7,6 & 14,5 & 1,9 & 0.735 (alto) \\
\hline Mato Grosso & 3.035 .122 & 10,5 & 15,7 & 2,1 & 0.725 (alto) \\
\hline Mato Grosso do Sul & 2.449 .024 & 9,9 & 17,2 & 2,0 & 0.729 (alto) \\
\hline Centro-Oeste & 14.058 .094 & 8,2 & 15,5 & 1,9 & 0.753 (alto) \\
\hline Brasil & 190.755 .799 & 15,2 & 17,2 & 1,9 & 0.721 (alto) \\
\hline
\end{tabular}

Fonte: IPEA, FJP, \& PNUD. Atlas do Desenvolvimento Humano no Brasil. http://www.atlasbrasil.org.br/

Notas: (1) \% de mães chefes de família sem ensino fundamental e com filho menor de 15 anos, no total de mães chefes de família.

(2) Número médio de filhos nascidos vivos por mulher com idade entre 15 e 49 anos. 
Em 2010, a população permanece concentrada notadamente nas regiões Sudeste $(42,1 \%)$ e Nordeste $(27,8 \%)$, detentoras de $70 \%$ dos habitantes do país. Em nível estadual, São Paulo $(21,6 \%)$ se destaca pela expressiva concentração populacional e, por outro lado, Roraima conta somente com $0,24 \%$. Outros indicadores ratificam essas diferenças regionais e estaduais, como é o caso da taxa de fecundidade total (número médio de filhos tidos por mulher) com os valores acima da média nacional (1,9 filhos por mulher) nas regiões Norte $(2,5$ filhos por mulher) e Nordeste ( 2,1 filhos por mulher), bem como para quase todos os estados dessas duas regiões, com exceção de Pernambuco (1,9 filhos por mulher), sendo marcante o resultado para o Acre (3,0 filhos por mulher) na região Norte e o Maranhão $(2,6$ filhos por mulher) na região Nordeste.

A proporção de pobres (ou seja, indivíduos com renda domiciliar per capita igual ou inferior a $\mathrm{R} \$ 140,00$ mensais, em Reais de agosto de 2010) foi mais acentuada nas regiões Norte ( $25,7 \%$ da população) e Nordeste (30,5\% da população), e menor nas demais regiões ( $5,5 \%$ no Sul, $8,1 \%$ no Sudeste e $8,2 \%$ no Centro-Oeste). Ademais, a pobreza alcançava proporções maiores em estados do Nordeste (com destaque para Alagoas com 34,3\% e Piauí com 34,1\%) e do Norte (Pará com 32,3\% e Amazonas com 30,8\%), ao passo que em Santa Catarina e em São Paulo essa porcentagem era bem menor (3,7\% e 4,7\% da população, respectivamente). Esse panorama revela os distintos 'Brasis', com algumas regiões desenvolvidas (Sul e Sudeste) e outras nem tanto, como são as regiões Norte e Nordeste.

O percentual de mães chefes de família sem ensino fundamental completo e com filhos menores de 15 anos também foi maior nas regiões Norte $(23,5 \%)$ e Nordeste $(22,8 \%)$, não sendo tão baixos os valores nas outras três grandes regiões, em média, com 14,5\% para cada. A distribuição estadual aponta, na região Norte, o Acre $(28,7 \%)$ com o pior resultado, e no Nordeste, Alagoas e Sergipe, ambos com 26,5\%, contra 17,2\% para o país (média nacional) e 13,2\% para São Paulo (Tabela 1).

O Índice de Desenvolvimento Humano Municipal brasileiro leva em consideração as três dimensões do IDH Global (esperança de vida ao nascer, educação e renda), adequando a metodologia do PNUD à realidade brasileira e à disponibilidade de indicadores no país. Outra vantagem de analisar o IDHM é porque o conceito de desenvolvimento está focado na condição dos indivíduos e não no crescimento econômico - mensurado pela variação do Produto Interno Bruto (PIB) - de um país, região, estado ou município.

É importante frisar que quanto mais próximo de 1 , maior o desenvolvimento humano. O IDHM é classificado da seguinte forma: 0,800-1,000 (muito alto); 0,700-0,799 (alto); 0,555-0,699 (médio); 0,350-0,554 (baixo). Sendo assim, dentre as 27 Unidades da Federação em estudo, em 2010, somente o Distrito Federal apresentou IDHM "muito alto" e 
12 estados IDHM "alto", sendo 10 nas regiões Sul, Sudeste e Centro-Oeste, e somente 02 no Norte (Amapá e Roraima). Portanto, os resultados do IDHM ratificam, em grande parte, as informações contidas na Tabela 1, que mostrou no mínimo dois "Brasis": i) aquele com os indicadores mais preocupantes, nas regiões Norte e Nordeste; ii) e aquele com índices mais desejáveis nas regiões Sul, Sudeste e Centro-Oeste.

\section{Resultados}

Com relação à inserção no mercado de trabalho, de acordo com a Tabela 2, a taxa de participação das mulheres é bem menor do que a dos homens em todos os 27 estados do Brasil, nos dois anos em estudo, não havendo grandes avanços ao longo de dez anos. Tanto em 2005 quanto em 2015, a taxa de participação feminina correspondia a 67\% da taxa masculina. Contudo, em nível estadual, confirmando a existência dos diferentes "Brasis", foi registrada maior disparidade em Rondônia no ano de 2005 (58\%) e em Alagoas em 2015 (55\%). Por outro lado, essa razão indica menor desigualdade de gênero (ainda que alta) no Distrito Federal, onde há maior porcentagem de trabalhadores no setor público: a proporcionalidade foi de $76 \%$ e $78 \%$, em 2005 e 2015, respectivamente.

Os estados mais ricos, situados nas regiões Sul e Sudeste do Brasil, em conjunto com o Distrito Federal, apresentam em 2005 e em 2015 as maiores taxas de participação das mulheres no mercado de trabalho, com valores iguais ou superiores à média nacional. Vale frisar que o Rio de Janeiro (em 2005) e o Espírito Santo (em 2015) foram as exceções, com uma razão ligeiramente inferior à média do país.

No tocante à participação nos afazeres domésticos (Tabela 2), o resultado se inverte, pois conforme a literatura, as mulheres são mais frequentes entre aqueles que se dedicam aos cuidados do domicílio e da família (Bilac, 2014). Portanto, no Brasil, a taxa de participação feminina em afazeres domésticos na semana de referência da pesquisa era $80 \%$ maior do que a masculina em 2005 e 74\% maior em 2015. Em nível regional, o Nordeste lidera a maior frequência de mulheres dedicadas aos afazeres domésticos quando comparada aos homens. Em Alagoas, por exemplo, a taxa feminina era 3 vezes maior que a masculina em 2005 e 2,5 vezes maior em 2015 - índices mais altos no país. Por outro lado, na região Sul essa razão é menor, mas ainda elevada. O estado com menor desproporção é o Rio Grande do Sul, onde a taxa feminina era 33\% maior do que a masculina em 2005 e $31 \%$ maior em 2015. 
Tabela 2. Razão da participação no mercado de trabalho e nos afazeres domésticos (mulheres / homens). Brasil: grandes regiões e Unidades da Federação, 2005 e 2015.

\begin{tabular}{|c|c|c|c|c|}
\hline \multirow[t]{2}{*}{ UF e grandes regiões } & \multicolumn{2}{|c|}{$\begin{array}{l}\text { Razão da participação no } \\
\text { mercado de trabalho }\end{array}$} & \multicolumn{2}{|c|}{$\begin{array}{l}\text { Razão da participação nos } \\
\text { afazeres domésticos }\end{array}$} \\
\hline & 2005 & 2015 & 2005 & 2015 \\
\hline Rondônia & 0,58 & 0,59 & 1,88 & 1,90 \\
\hline Acre & 0,64 & 0,57 & 1,80 & 1,60 \\
\hline Amazonas & 0,62 & 0,62 & 1,56 & 1,50 \\
\hline Roraima & 0,68 & 0,66 & 1,65 & 1,47 \\
\hline Pará & 0,59 & 0,56 & 1,86 & 1,75 \\
\hline Amapá & 0,62 & 0,59 & 1,88 & 1,76 \\
\hline Tocantins & 0,64 & 0,61 & 1,63 & 2,12 \\
\hline Norte & 0,63 & 0,60 & 1,75 & 1,73 \\
\hline Maranhão & 0,60 & 0,61 & 2,29 & 1,91 \\
\hline Piauí & 0,63 & 0,68 & 1,63 & 1,92 \\
\hline Ceará & 0,66 & 0,64 & 1,95 & 2,09 \\
\hline Rio Grande do Norte & 0,58 & 0,64 & 2,34 & 2,16 \\
\hline Paraíba & 0,68 & 0,65 & 1,70 & 1,67 \\
\hline Pernambuco & 0,62 & 0,63 & 2,15 & 2,33 \\
\hline Alagoas & 0,59 & 0,55 & 2,99 & 2,51 \\
\hline Sergipe & 0,67 & 0,67 & 2,07 & 1,89 \\
\hline Bahia & 0,64 & 0,65 & 1,70 & 1,80 \\
\hline Nordeste & 0,63 & 0,64 & 2,09 & 2,03 \\
\hline Minas Gerais & 0,67 & 0,71 & 1,94 & 1,57 \\
\hline Espírito Santo & 0,69 & 0,65 & 1,90 & 1,87 \\
\hline Rio de Janeiro & 0,66 & 0,69 & 1,93 & 1,96 \\
\hline São Paulo & 0,70 & 0,75 & 1,71 & 1,63 \\
\hline Sudeste & 0,68 & 0,70 & 1,87 & 1,76 \\
\hline Paraná & 0,70 & 0,71 & 1,58 & 1,62 \\
\hline Santa Catarina & 0,72 & 0,73 & 1,73 & 1,63 \\
\hline Rio Grande do Sul & 0,73 & 0,76 & 1,33 & 1,31 \\
\hline Sul & 0,72 & 0,73 & 1,55 & 1,52 \\
\hline Mato Grosso do Sul & 0,68 & 0,68 & 1,78 & 1,55 \\
\hline Mato Grosso & 0,62 & 0,65 & 1,81 & 1,78 \\
\hline Goiás & 0,63 & 0,68 & 2,01 & 1,88 \\
\hline Distrito Federal & 0,76 & 0,78 & 1,46 & 1,39 \\
\hline Centro-Oeste & 0,67 & 0,70 & 1,77 & 1,65 \\
\hline Brasil & 0,67 & 0,67 & 1,80 & 1,74 \\
\hline
\end{tabular}

Fonte: IBGE. PNAD, 2005 e 2015. Elaboração própria.

Para ambos os indicadores, os Mapas 1 e 2 evidenciam que na maioria dos estados houve redução nas desigualdades de gênero, entre 2005 e 2015, mas em magnitudes diferentes, com aumento da participação das mulheres em relação aos homens no mercado de trabalho (Mapa 1) e redução da participação feminina nos afazeres domésticos (Mapa 2). 
Mapa 1. Variação relativa da razão da participação no mercado de trabalho, por UF (2005-2015).

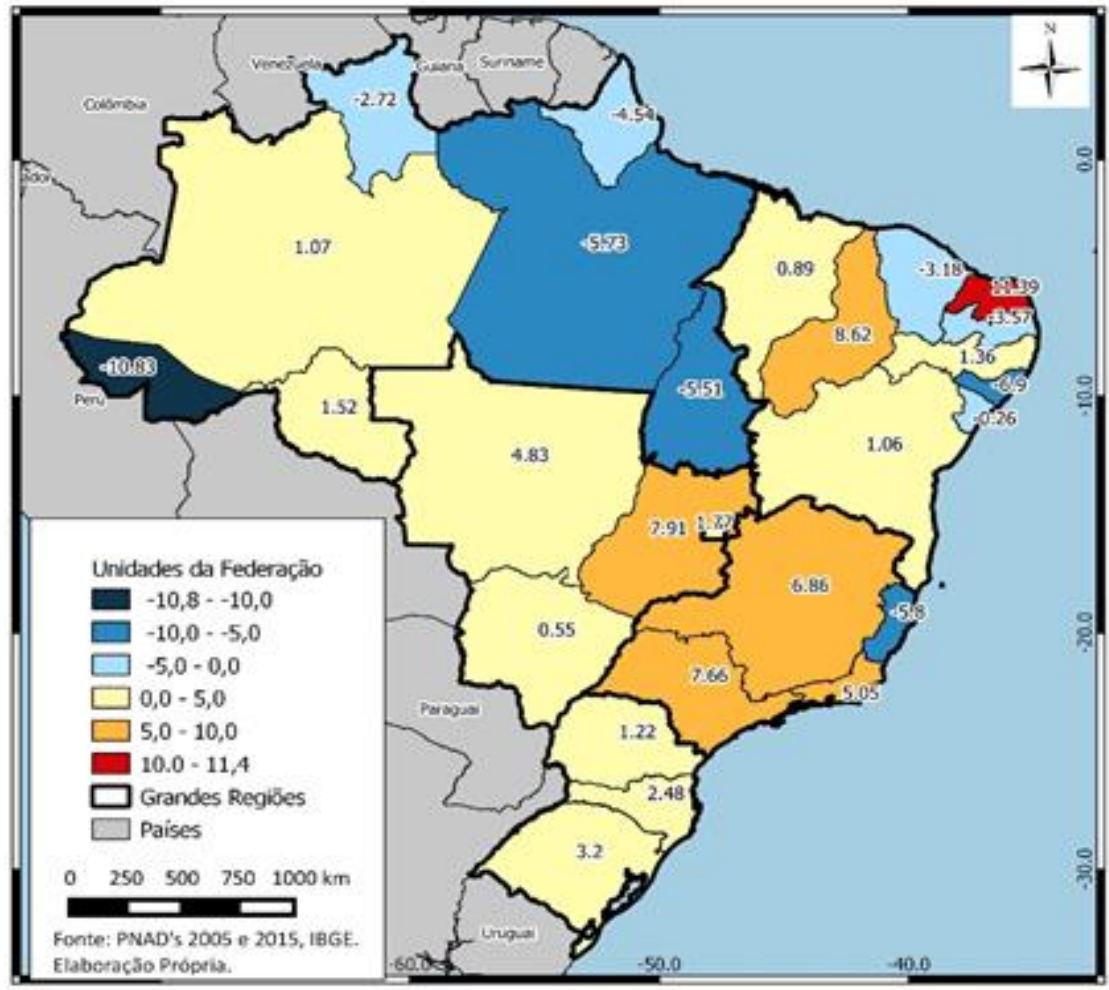

Fonte: IBGE. PNAD 2005 e 2015; IBGE. Malha Digital do Brasil. Elaboração própria.

Mapa 2. Variação relativa da razão da participação nos afazeres domésticos, por UF (2005-2015).

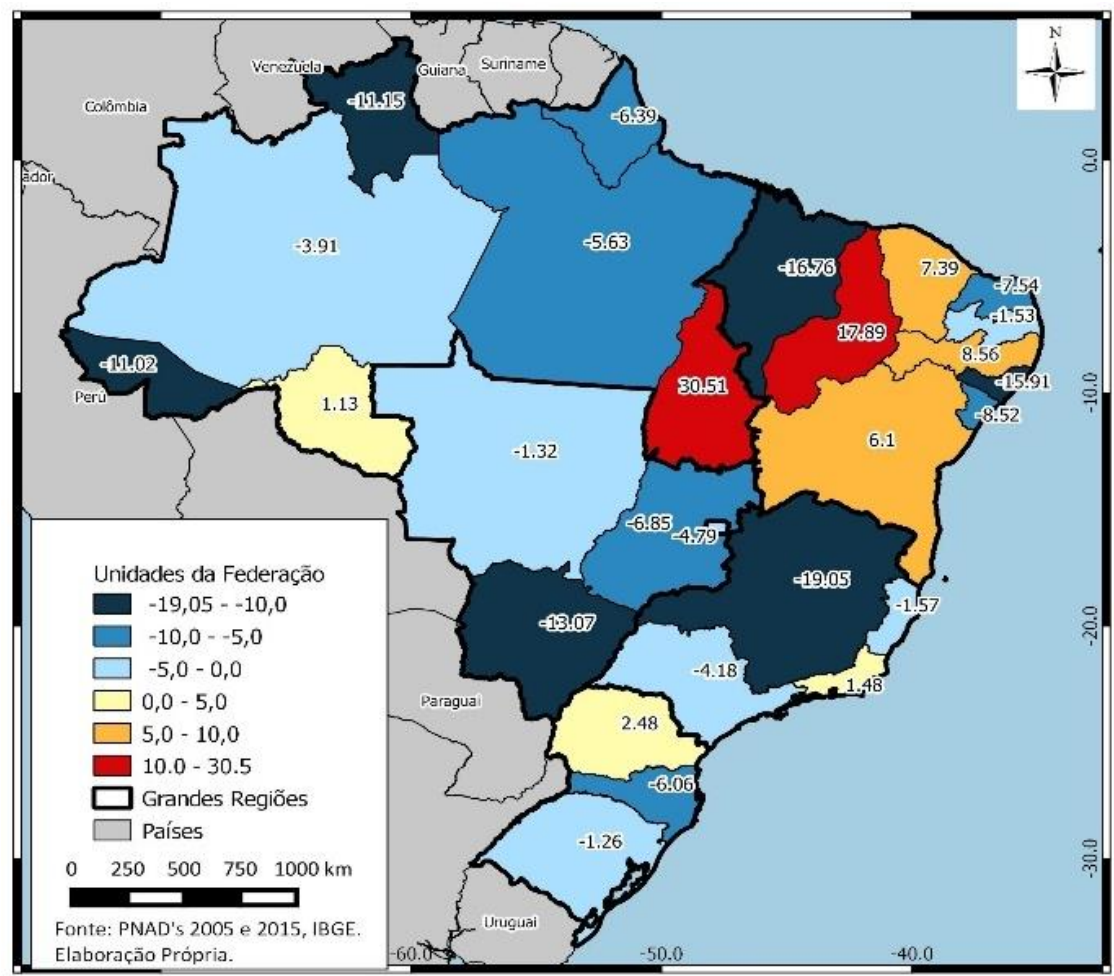

Fonte: IBGE. PNAD 2005 e 2015; IBGE. Malha Digital do Brasil. Elaboração própria. 
Esse resultado era esperado, na medida em que as mulheres cada vez mais se inserem no mercado de trabalho e necessitam dividir as atividades domésticas com os demais integrantes do domicílio. Contudo, entre os 26 estados brasileiros e o Distrito Federal, nove estados na escala azul (Mapa 1) tiveram declínio na razão da participação no mercado de trabalho (cinco da região Norte, quatro do Nordeste e apenas o Espírito Santo da região Sudeste). Portanto, houve aumento da desigualdade de gênero nesses estados.

Os estados do Acre e Alagoas foram aqueles onde mais se reduziu a razão entre mulheres e homens no mercado de trabalho (10,8\% e 6,9\%, respectivamente), entre 2005 e 2015. Cabe ressaltar que o ano de 2015 foi o início da recessão econômica e da crise política no país, que afetaram de forma distinta os diferentes contextos estaduais. Nas regiões Norte e Nordeste, a perda de dinamismo afetou a geração de empregos de forma mais intensa, reduzindo a participação no mercado de trabalho, principalmente das mulheres. Essa observação para o ano de 2015 é congruente com o estudo de Aparício e Queiroz (2012) para a Região Metropolitana de São Paulo (RMSP) e Região Metropolitana de Fortaleza (RMF), que analisou os impactos da crise de 2008 sobre o mercado de trabalho dessas duas metrópoles.

Com relação à participação nos afazeres domésticos (Mapa 2), o indicador mostrou aumento da desigualdade (taxa das mulheres em relação à taxa dos homens) principalmente no Tocantins $(30,5 \%)$, no Piauí $(17,9 \%)$, em Pernambuco $(8,6 \%)$, no Ceará $(7,4 \%)$, e na Bahia (6,2\%). Os estados nordestinos são culturalmente mais contaminados pelo patriarcado, o que se manifesta na divisão sexual do trabalho (Lopes, Myrrha, \& Queiroz, 2019, novembro). Considerando que 2015 foi um ano de recessão econômica, contexto que dificulta a permanência e a inserção da mulher no mercado de trabalho, é possível que elas não tenham conseguido emprego, com isso, ficaram desempregadas e retomaram a posição de donas de casa. E que os homens tenham assumido o papel de provedor financeiro e, por isso, deixado de participar dos afazeres domésticos.

Por outro lado, em Minas Gerais (19,1\%), no Maranhão (16,8\%), em Alagoas $(15,9 \%)$, Mato Grosso do Sul $(13,1 \%)$, em Roraima $(11,2 \%)$ e no Acre $(11,0 \%)$ houve diminuição nesse indicador de desigualdade, com redução de mais de $10 \%$ em termos proporcionais na razão das participações de mulheres e homens em afazeres domésticos.

Em relação às desigualdades no tempo dedicado ao trabalho remunerado e aos afazeres domésticos, também se observam índices superiores para os homens na esfera produtiva e para as mulheres na esfera reprodutiva, em todos os estados brasileiros, nesse período (Tabela 3). Os dados indicam uma mudança lenta na divisão sexual do trabalho, ainda predominando os papéis de gênero específicos e definidos, cabendo à mulher o cuidado do lar, dos idosos e crianças, enquanto ao homem cabe o papel de provedor (Kergoat, 2003). 
Tabela 3: Razão (mulheres / homens) da jornada de trabalho semanal média, do tempo médio dedicado aos afazeres domésticos e do tempo médio total gasto com ambos. Brasil, grandes regiões e Unidades da Federação: 2005 e 2015.

\begin{tabular}{|c|c|c|c|c|c|c|}
\hline \multirow[t]{2}{*}{ UF e grande região } & \multicolumn{2}{|c|}{$\begin{array}{l}\text { Razão da jornada de } \\
\text { trabalho semanal }\end{array}$} & \multicolumn{2}{|c|}{$\begin{array}{l}\text { Razão do tempo dedicado } \\
\text { aos afazeres domésticos }\end{array}$} & \multicolumn{2}{|c|}{$\begin{array}{l}\text { Razão do tempo total } \\
\text { gasto com ambos }\end{array}$} \\
\hline & 2005 & 2015 & 2005 & 2015 & 2005 & 2015 \\
\hline Rondônia & 0,79 & 0,90 & 2,55 & 2,24 & 1,04 & 1,14 \\
\hline Acre & 0,81 & 0,87 & 2,42 & 1,88 & 1,06 & 1,06 \\
\hline Amazonas & 0,87 & 0,90 & 1,51 & 1,85 & 0,99 & 1,08 \\
\hline Roraima & 0,86 & 0,88 & 2,03 & 1,83 & 1,08 & 1,05 \\
\hline Pará & 0,80 & 0,84 & 2,27 & 2,01 & 1,05 & 1,06 \\
\hline Amapá & 0,86 & 0,91 & 2,10 & 1,62 & 1,11 & 1,07 \\
\hline Tocantins & 0,78 & 0,85 & 2,53 & 1,86 & 1,05 & 1,06 \\
\hline Norte & 0,82 & 0,88 & 2,20 & 1,90 & 1,06 & 1,08 \\
\hline Maranhão & 0,78 & 0,80 & 2,57 & 2,20 & 1,12 & 1,10 \\
\hline Piauí & 0,66 & 0,78 & 2,64 & 2,42 & 1,04 & 1,11 \\
\hline Ceará & 0,81 & 0,91 & 2,40 & 1,92 & 1,10 & 1,14 \\
\hline Rio Grande do Norte & 0,83 & 0,86 & 2,64 & 1,99 & 1,14 & 1,09 \\
\hline Paraíba & 0,79 & 0,81 & 2,47 & 2,18 & 1,13 & 1,13 \\
\hline Pernambuco & 0,82 & 0,88 & 2,40 & 2,08 & 1,14 & 1,12 \\
\hline Alagoas & 0,84 & 0,92 & 2,05 & 1,99 & 1,08 & 1,16 \\
\hline Sergipe & 0,81 & 0,85 & 2,38 & 2,30 & 1,12 & 1,16 \\
\hline Bahia & 0,81 & 0,86 & 2,26 & 2,09 & 1,07 & 1,10 \\
\hline Nordeste & 0,79 & 0,85 & 2,42 & 2,13 & 1,10 & 1,12 \\
\hline Minas Gerais & 0,82 & 0,85 & 2,49 & 2,16 & 1,09 & 1,09 \\
\hline Espírito Santo & 0,81 & 0,87 & 2,31 & 2,09 & 1,08 & 1,09 \\
\hline Rio de Janeiro & 0,85 & 0,89 & 2,18 & 1,63 & 1,10 & 1,05 \\
\hline São Paulo & 0,86 & 0,89 & 2,30 & 2,00 & 1,09 & 1,09 \\
\hline Sudeste & 0,83 & 0,88 & 2,32 & 1,97 & 1,09 & 1,08 \\
\hline Paraná & 0,81 & 0,88 & 2,41 & 2,02 & 1,07 & 1,08 \\
\hline Santa Catarina & 0,84 & 0,89 & 2,37 & 1,99 & 1,08 & 1,10 \\
\hline Rio Grande do Sul & 0,83 & 0,87 & 2,38 & 2,09 & 1,07 & 1,09 \\
\hline Sul & 0,83 & 0,88 & 2,39 & 2,03 & 1,07 & 1,09 \\
\hline Mato Grosso do Sul & 0,80 & 0,83 & 2,42 & 2,02 & 1,04 & 1,02 \\
\hline Mato Grosso & 0,81 & 0,87 & 2,06 & 1,96 & 1,03 & 1,07 \\
\hline Goiás & 0,82 & 0,86 & 2,31 & 2,09 & 1,06 & 1,08 \\
\hline Distrito Federal & 0,90 & 0,92 & 2,19 & 1,76 & 1,12 & 1,09 \\
\hline Centro-Oeste & 0,83 & 0,87 & 2,24 & 1,96 & 1,06 & 1,06 \\
\hline Brasil & 0,82 & 0,87 & 2,32 & 2,00 & 1,08 & 1,09 \\
\hline
\end{tabular}

Fonte: IBGE. PNAD 2005 e 2015. Elaboração própria.

No Brasil como um todo, para cada 10 horas semanais dedicadas pelos homens ao trabalho remunerado, as mulheres dedicaram, em média, 8 horas e 15 minutos em 2005 e 8 horas e 42 minutos em 2015. Ou seja, de fato, os homens possuem uma jornada de trabalho 
remunerado maior, mas essa diferença reduziu-se no intervalo em estudo e não varia muito por estado, mas é maior na região Nordeste. No Piauí e no Maranhão, as mulheres tinham uma jornada de trabalho $20 \%$ menor do que a dos homens (Tabela 3). Uma possível justificativa é que nesses estados os trabalhos são mais precários.

A magnitude dos diferenciais no tempo gasto com os afazeres domésticos é consideravelmente maior do que no tempo dedicado ao trabalho remunerado. Na maioria dos estados, as mulheres dedicam ao domicílio e aos cuidados familiares mais do que o dobro do tempo dedicado pelos homens. Mas, essa desigualdade de gênero diminuiu no período. No Brasil, para cada 10 horas dedicadas pelos homens aos afazeres domésticos, as mulheres dedicavam, em média, 23 horas e 20 minutos em 2005 e 20 horas em 2015 (Tabela 3). Em nível estadual, a disparidade é maior no Piauí, onde elas dedicavam um tempo 2,42 vezes maior do que os homens em 2015. Em Sergipe, 2,30 vezes maior. Por sua vez, essa disparidade é menor no Rio de Janeiro e no Distrito Federal (onde o peso do emprego público é relevante, inclusive entre as mulheres), mas ainda assim expressiva. De um modo geral, a sociedade e o mundo do trabalho ainda reproduzem uma segregação ocupacional, rotulando muitas ocupações como inerentemente "femininas" ou "masculinas", perpetuando as desigualdades entre homens e mulheres (Daniel, 2011).

A razão do tempo médio total dedicado ao trabalho remunerado e ao trabalho reprodutivo por mulheres e por homens evidencia que, em todos os estados, o número de horas semanais declarado pelas mulheres é maior. Não houve mudança significativa do quadro geral no período analisado. No Brasil, em 2015, as mulheres tinham uma dedicação total, em média, $9 \%$ maior do que a dos homens.

Quanto aos estados, novamente, os localizados no Nordeste possuem os piores resultados, com agravamento na maioria dos casos ao longo do decênio. Em 2015, em Sergipe e em Alagoas, as mulheres dedicavam, em média, um tempo total $16 \%$ maior do que os homens. Por outro lado, no Mato Grosso do Sul a diferença era de apenas $2 \%$. Tais achados estão em sintonia com o estudo sobre "desigualdade de gênero em tempo de trabalho pago e não pago no Brasil", de Medeiros e Pinheiro (2018). Os autores constatam que, em 2013, um dos principais determinantes do diferencial de gênero estava relacionado com a proporção de indivíduos que realizam trabalho pago (mercantilizado) e com a duração/tempo dedicado ao trabalho não pago (reprodutivo). Sendo assim, o tipo de ocupação é o fator que mais diferencia homens de mulheres, pois eles empregam mais tempo em trabalho remunerado e menos tempo no trabalho reprodutivo; por outro lado, elas apresentam jornadas de trabalho pagas em níveis inferiores às deles, mas longas horas de trabalho não pago. Portanto, o tempo total de trabalho delas é superior ao deles, isto é, as mulheres geralmente trabalham mais. 
De 2005 para 2015, em todos os estados brasileiros a razão do tempo dedicado ao trabalho remunerado aumentou porque as mulheres aumentaram o tempo gasto com trabalho fora de casa. Por outro lado, com exceção do Amazonas, o tempo dedicado aos afazeres domésticos das mulheres (em comparação com o dos homens) diminuiu em todos os estados brasileiros (Tabela 3). O comportamento de ambos os indicadores sugere uma redução na desigualdade de gênero, mas se considerarmos o tempo total de trabalho, as desigualdades cresceram levemente em 17 estados brasileiros (Mapa 3).

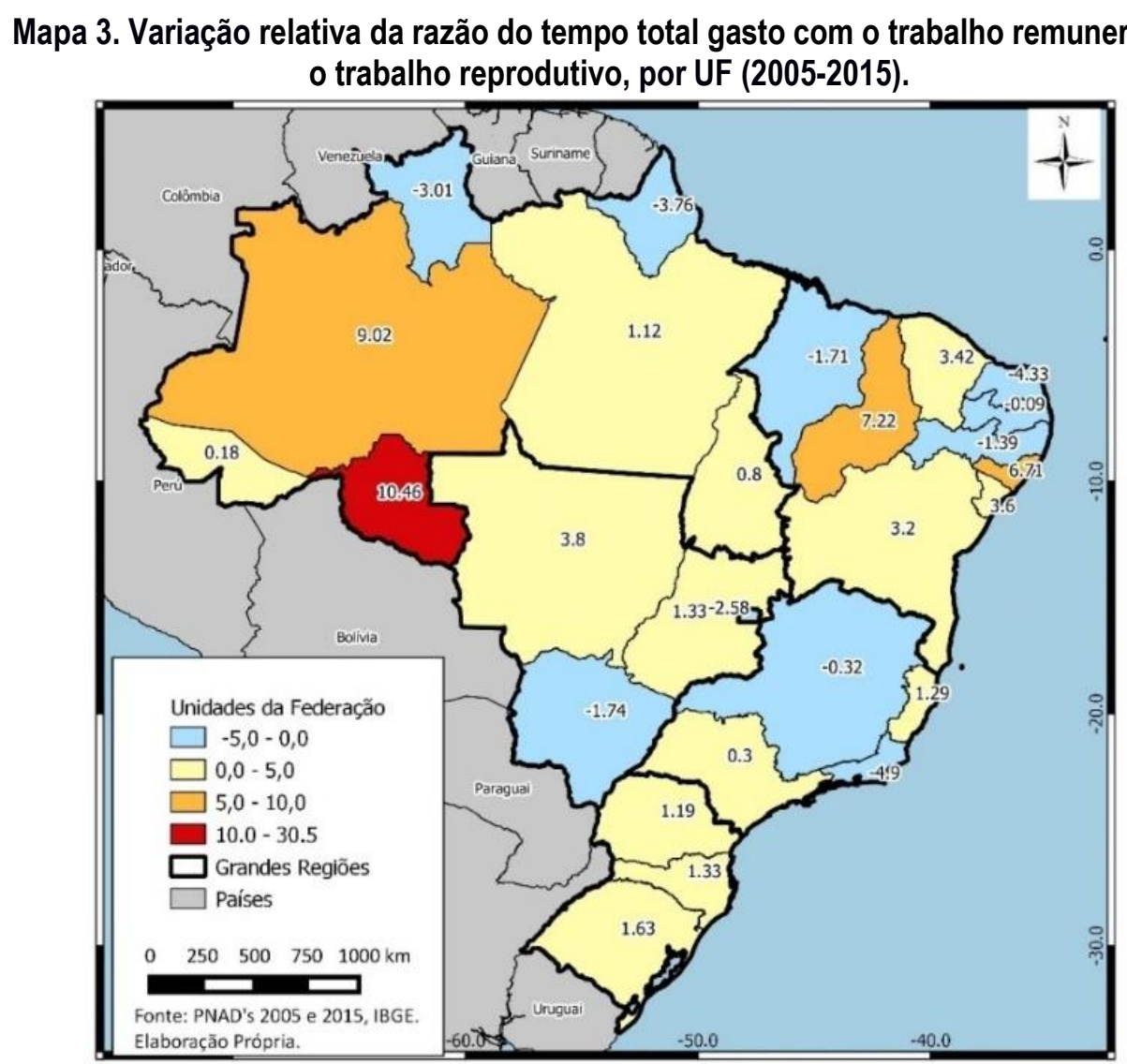

Fonte: IBGE. PNAD 2005 e 2015; IBGE. Malha Digital do Brasil. Elaboração própria.

No tocante aos rendimentos advindos do mercado de trabalho, a razão do salário médio por hora das mulheres em relação ao dos homens é menor do que a unidade na grande maioria dos estados brasileiros (Tabela 4 e Mapa 4). Considerando o conjunto do país, houve uma pequena redução na diferença de remuneração de 2005 para 2015: as mulheres tinham rendimento médio que correspondia a $81 \%$ do valor médio dos homens em 2005; essa proporção aumentou para $87 \%$ em 2015 . Mas, a desigualdade de gênero se manteve. ${ }^{2}$

\footnotetext{
2 Teixeira (2014), analisando apenas o emprego formal, aponta a permanecia das desigualdades
} salariais entre homens e mulheres no período 2003-2013 (a razão se manteve em 83\% no período). 
Tabela 4. Razão do salário médio por hora das mulheres em relação ao dos homens. Brasil, grandes regiões e Unidades da Federação: 2005 e 2015.

\begin{tabular}{|c|c|c|}
\hline UF e grande região & 2005 & 2015 \\
\hline Rondônia & 0,83 & 0,88 \\
\hline Acre & 0,94 & 0,82 \\
\hline Amazonas & 0,77 & 0,95 \\
\hline Roraima & 0,99 & 1,14 \\
\hline Pará & 0,82 & 0,98 \\
\hline Amapá & 0,87 & 1,03 \\
\hline Tocantins & 0,96 & 1,05 \\
\hline Norte & 0,88 & 0,98 \\
\hline Maranhão & 0,91 & 0,96 \\
\hline Piauí & 1,04 & 0,98 \\
\hline Ceará & 0,89 & 0,97 \\
\hline Rio Grande do Norte & 1,02 & 1,00 \\
\hline Paraíba & 0,93 & 0,92 \\
\hline Pernambuco & 0,89 & 0,92 \\
\hline Alagoas & 0,86 & 1,05 \\
\hline Sergipe & 0,75 & 0,95 \\
\hline Bahia & 0,84 & 0,90 \\
\hline Nordeste & 0,90 & 0,96 \\
\hline Minas Gerais & 0,78 & 0,80 \\
\hline Espírito Santo & 0,74 & 0,84 \\
\hline Rio de Janeiro & 0,82 & 0,89 \\
\hline São Paulo & 0,76 & 0,80 \\
\hline Sudeste & 0,78 & 0,83 \\
\hline Paraná & 0,74 & 0,78 \\
\hline Santa Catarina & 0,66 & 0,77 \\
\hline Rio Grande do Sul & 0,73 & 0,83 \\
\hline Sul & 0,71 & 0,79 \\
\hline Mato Grosso do Sul & 0,80 & 0,82 \\
\hline Mato Grosso & 0,77 & 0,78 \\
\hline Goiás & 0,78 & 0,80 \\
\hline Distrito Federal & 0,80 & 0,83 \\
\hline Centro-Oeste & 0,79 & 0,81 \\
\hline Brasil & 0,81 & 0,87 \\
\hline
\end{tabular}

Fonte: IBGE. PNAD 2005 e 2015. Elaboração própria.

É importante esclarecer que as diferenças salariais entre homens e mulheres são maiores nas regiões Sul, Sudeste e Centro-Oeste, e menores nas regiões Norte e Nordeste, onde é maior a proporção de trabalhadores que recebem baixos salários. Em 2005, esse 
indicador foi um pouco superior à unidade em dois estados: Ceará e Rio Grande do Norte. Em 2015, em cinco estados o salário médio por hora das mulheres foi igual ou superior ao dos homens, com destaque para Roraima (14\%).

Por outro lado, em vários estados essa razão se distancia da unidade, evidenciando que a hora trabalhada da mulher custa menos que a hora trabalhada do homem. A desigualdade é maior em Santa Catarina - um dos estados mais ricos do Brasil, que detém bons indicadores socioeconômicos, demográficos e de rendimento. Nesse estado, em 2005, as mulheres tinham rendimento médio que correspondia a apenas $66 \%$ do valor médio dos homens; em 2015, essa proporção havia aumentado para 77\%. No Paraná e no Mato Grosso, as mulheres recebiam, em média, um valor $22 \%$ menor do que os homens. Em São Paulo, em Minas Gerais e em Goiás, 20\% a menos, em 2015.

Mapa 4. Razão da média salarial de mulheres e de homens, por UF (2015).

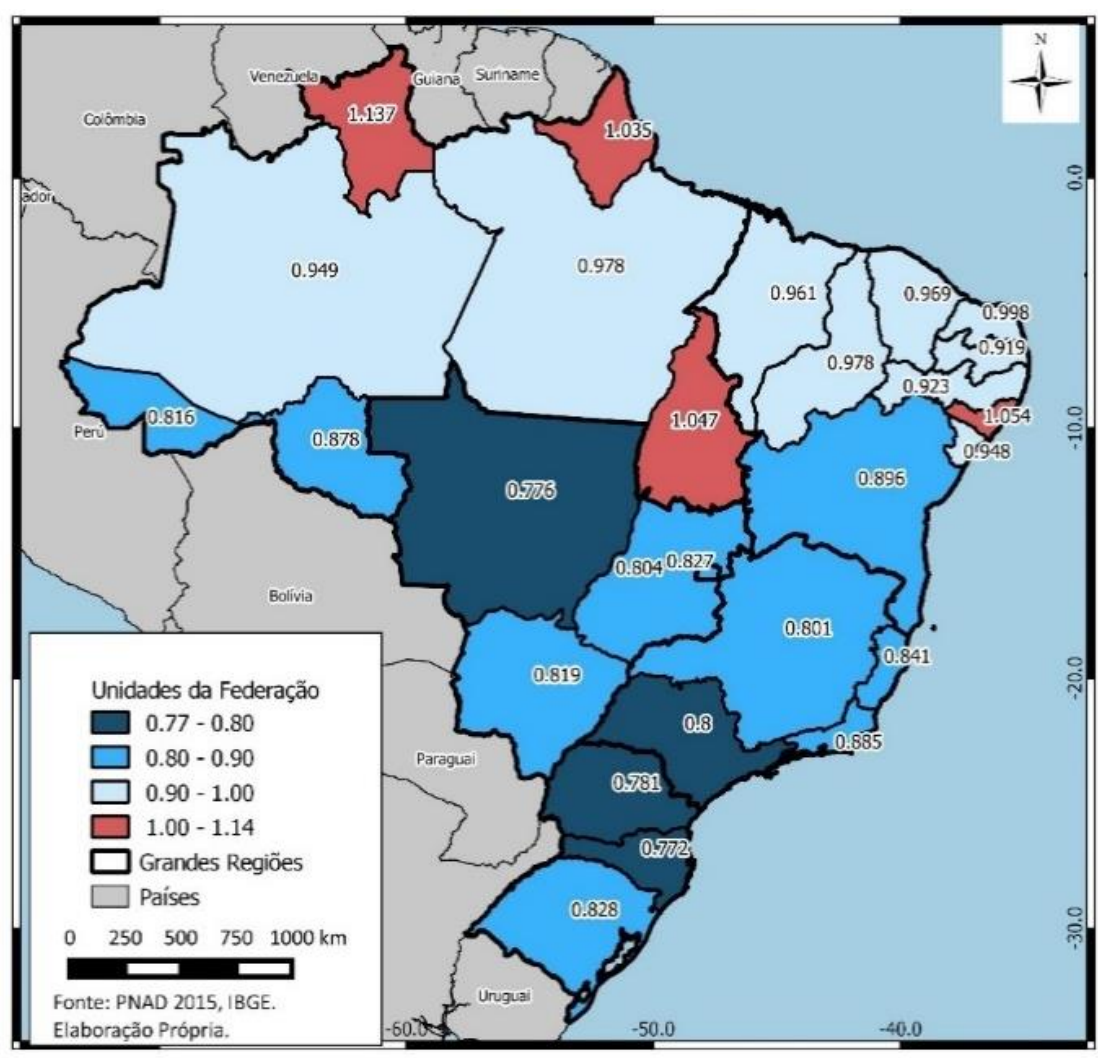

Fonte: IBGE. PNAD 2005 e 2015; IBGE. Malha Digital do Brasil. Elaboração própria.

O Mapa 4 ilustra os resultados da Tabela 4 ao mostrar a distribuição espacial da desigualdade de gênero nos rendimentos em 2015. Os estados pintados de azul escuro se destacam pelo maior diferencial em favor dos homens, enquanto os estados pintados de 
vermelho indicam maior rendimento horário das mulheres. Estudos evidenciam que quanto maior a escolaridade e melhores os cargos, maior é desigualdade salarial entre homens e mulheres, com vantagem para eles. Portanto, a maior igualdade de gênero de rendimentos nos estados mais pobres pode ser justificada pela menor diferença salarial nas ocupações que exigem menor qualificação, as quais são mais frequentes nos estados do Norte e do Nordeste.

Em um estudo técnico para a Câmara dos Deputados, T. Andrade (2016) trata de saber onde nasce a desigualdade das mulheres em relação aos homens no mercado de trabalho brasileiro. Apesar dos inúmeros avanços nos últimos 30 anos, muito ainda terá de ser conquistado. Porque, segundo a autora, a barreira enfrentada por elas no mundo do trabalho vai além da discriminação de gênero, está associada com a discriminação racial (cor da pele negra) e é reforçada pela discriminação por origem, idade, orientação sexual, gravidez, doença e deficiência. Assim, ser mulher e trabalhadora é difícil. Ser mulher trabalhadora e ganhar igual ao homem que exerce a mesma função é mais difícil. Ser mulher e assumir cargos de responsabilidade/chefia, muito difícil. Comprovadamente, ser mulher trabalhadora e negra é dificílimo. E ser mulher chefe de família e mãe, mais difícil. Portanto, aí é onde nasce a desigualdade de gênero.

Abramo (2005) aponta que mesmo as mulheres brasileiras sendo mais escolarizadas, essa conquista não se traduziu em rendimentos iguais aos dos homens nem arrefeceu expressivamente o "gap" salarial. Permanece elevada a participação delas em ocupações vulneráveis e de baixo rendimento, como o serviço doméstico, embora a maior escolaridade tenha contribuído para aumentar os rendimentos médios do trabalho feminino (Lameirão, 2011).

Os indicadores demonstram que o Brasil é heterogêneo em termos de desigualdade de gênero em nível regional e estadual, e que na maioria dos estados houve redução das desigualdades entre 2005 e 2015, mas em alguns houve piora em certos aspectos. Os indicadores de participação no mercado de trabalho e no trabalho reprodutivo sugerem que nos estados mais pobres as desigualdades são maiores. Com relação à remuneração média, as desigualdades são maiores nos estados mais ricos, devido à maior oferta de empregos que exigem maior qualificação, nos quais as desigualdades salariais são maiores.

Ademais, segundo Hirata (2015), em um contexto desfavorável (crise política, recessão econômica, políticas neoliberais, privatizações e diminuição na oferta de emprego público e privado, bem como dos serviços públicos), as consequências são diferentes conforme o sexo do trabalhador, ou melhor, as mulheres são mais penalizadas. Assim, é importante reconhecer que o contexto político e econômico tem influência significativa na participação e na remuneração de ambos os sexos no mercado de trabalho. 
No ano de 2015, o Brasil iniciou um contexto político e econômico bastante desfavorável, o que resultou numa piora considerável do mercado de trabalho, com aumento do desemprego e da informalidade, problemas que permaneceram nos anos seguintes. Nesse sentido, as diferenças entre os estados e grandes regiões nos indicadores selecionados podem ter sido influenciadas por esse contexto, apesar da desigualdade de gênero no Brasil não ser um problema conjuntural, mas sim estrutural.

\section{Considerações finais}

Neste artigo foi possível observar que a participação das mulheres no mercado de trabalho é menor do que a dos homens em todo o país, e não ocorreram avanços importantes entre 2005 e 2015, sendo que os estados mais desenvolvidos (regiões Sul e Sudeste) dispõem das maiores taxas de participação feminina. Já em relação à participação nos afazeres domésticos, observou-se pequena redução da frequência de mulheres em comparação com os homens, sendo que nas regiões mais pobres (Norte e Nordeste) essa desigualdade é maior.

Além disso, constatou-se piora no indicador de participação no mercado de trabalho (concentrada em alguns estados das regiões Norte e Nordeste) e no relativo à participação em afazeres domésticos (novamente na maioria dos estados da região Nordeste). Mas foi feita a ressalva de que as diferenças regionais nas desigualdades de gênero também são influenciadas pela conjuntura econômica e política.

Em relação ao tempo dedicado ao trabalho remunerado e aos afazeres domésticos, se observa a superioridade dos homens na esfera produtiva e das mulheres na esfera reprodutiva, sendo bem maiores os diferenciais no tempo gasto com os afazeres domésticos se comparados às diferenças do tempo gasto com o trabalho remunerado. As diferenças na jornada de trabalho remunerado são menores nas regiões Norte e Nordeste, possivelmente devido à precariedade das ocupações nessas regiões, somada à pouca flexibilidade de horário para as mulheres, e ainda à necessidade de trabalhar mais horas por causa do baixo rendimento horário.

A razão do tempo total de trabalho (somando a dedicação ao trabalho remunerado e aos afazeres domésticos) evidencia que, em todos os estados, as mulheres são geralmente obrigadas a trabalhar por mais tempo do que os homens, sendo o Nordeste a região que apresentou novamente os piores resultados. Embora tenha se observado, entre 2005 e 2015, aumento da razão do tempo dedicado ao trabalho remunerado (em todos os estados) e redução da razão no tempo dedicado aos afazeres domésticos (exceção ao Amazonas) - o que sugere uma redução da desigualdade de gênero no tempo de trabalho - ainda que o indicador referente ao tempo total de trabalho tenha aumentado um pouco em 16 estados. 
As maiores desigualdades de rendimento foram registradas nas regiões Sul e Sudeste, resultado associado à maior proporção de bons empregos e de ocupações que propiciam alta renda nessas regiões, o que resulta numa maior desigualdade salarial a favor dos homens. Nas regiões mais pobres, onde é elevada a porcentagem de trabalhos precários (com menor exigência de qualificação), a diferença salarial é menor. Certamente, é desejável que a redução na desigualdade seja acompanhada de elevação dos rendimentos e não como uma consequência da precarização do mercado de trabalho.

Por fim, é preciso ressaltar que as diferenças regionais na desigualdade de gênero permitem qualificar a discussão sobre os avanços observados no Brasil no período analisado. Em adição, deve-se ressaltar a relevância de avançar em estudos que tratem da desigualdade em unidades administrativas menores, diante da grande heterogeneidade existente no país.

\section{Referências}

Andrade, V. R. P. (2005). A soberania patriarcal: o sistema de justiça criminal no tratamento da violência sexual contra a mulher. Revista Seqüência, 26(50), 71-102.

https://doi.org/10.5007/\%25x

Andrade, T. (2016). Mulheres no mercado de trabalho: onde nasce a desigualdade? [Estudo Técnico, julho/2016], Consultoria Legislativa, Câmara dos Deputados, Distrito Federal. https://bd.camara.leg.br/bd/handle/bdcamara/29160

Abramo, L. (2005). Desigualdades e discriminação de gênero e raça no mercado de trabalho brasileiro e suas implicações para a formulação de uma política de emprego. In $\mathrm{H}$. da Costa \& M. da Conceição (Orgs.), Educação integral e sistema de reconhecimento e certificação educacional e profissional (vol.1, pp. 91-120). São Paulo: CUT.

Aparício, C. A. P., \& Queiroz, S. N. de (2012). Mercado de trabalho pós-crise: comparação entre as regiões metropolitanas de São Paulo e Fortaleza (2009 e 2010). In I. T. Moreira \& R. V. Oliveira (Orgs.). Cenários da crise e do trabalho no Brasil (vol. 1, pp. 157-187). João Pessoa: Editora Universitária da UFPB.

Araújo, T. B. de (2009). Desenvolvimento regional no Brasil. In C. Furtado et al., $O$ pensamento de Celso Furtado e o Nordeste hoje (pp. 33-44). Rio de Janeiro: Contraponto; Centro Internacional Celso Furtado de Políticas para o Desenvolvimento; Banco do Nordeste do Brasil.

Bilac, E. D. (2014). Trabalho e família: articulações possíveis. Tempo Social, 26(1), 129145. https://www.scielo.br/j/ts/a/6Y8y3TwKqbg4dKHfGfPkXTB/?format=pdf\&lang=pt

Bruschini, M. C. A. (2007). Trabalho e gênero no Brasil nos últimos dez anos. Cadernos de Pesquisa, 37(132), 537-572. https://doi.org/10.1590/S0100-15742007000300003 
Cano, W., \& Guimarães Neto, L. (1986). A questão regional no Brasil: traços gerais e sua evolução histórica. Revista de Economia Política, 10, 167-184.

Daniel, C. (2011). O trabalho e a questão de gênero: a participação de mulheres no mercado de trabalho. O Social em Questão, 14(25/26), 323-344. http://osocialemquestao.ser.puc-rio.br/media/17 OSQ $25 \quad 26$ Daniel.pdf

Dedecca, C. S. (2008). Regimes de trabalho, uso do tempo e desigualdade entre homens e mulheres. In A. de O. Costa, B. Sorj, C. Bruschini, \& H. Hirata (Orgs.), Mercado de trabalho e gênero: Comparações internacionais (vol. 1, pp. 279-298). Rio de Janeiro: Editora FGV.

Delphy, C. (2013). L'ennemi principal. Tome 1: Économie politique du patriarcat. 3rd ed. Paris: Éditions Syllepse.

Hirata, H. (2015). Mudanças e permanências nas desigualdades de gênero: divisão sexual do trabalho numa perspectiva comparativa. [Análise, n. 7/2015], Friedrich Ebert Stiftung (FES) Brasil, São Paulo. https://library.fes.de/pdf-files/bueros/brasilien/12133.pdf

Instituto Brasileiro de Geografia e Estatística - IBGE (2005). Pesquisa Nacional por Amostra de Domicílios - PNAD: 2005. Rio de Janeiro, RJ: IBGE.

Instituto Brasileiro de Geografia e Estatística - IBGE (2015). Pesquisa Nacional por Amostra de Domicílios - PNAD: 2015. Rio de Janeiro, RJ: IBGE.

Jesus, J. C. de (2018). Trabalho doméstico não remunerado no Brasil: Uma análise de produção, consumo e transferência. (Tese de Doutorado em Demografia). Centro de Desenvolvimento e Planejamento Regional, Faculdade de Ciências Econômicas, Universidade Federal de Minas Gerais. https://repositorio.ufmg.br/handle/1843/FACE-B27PW9

Kergoat, D. (2003). Divisão sexual do trabalho e relações sociais de sexo. In M. Teixeira, M. Emílio, M. Nobre, \& T. Godinho (Orgs.), Trabalho e cidadania ativa para as mulheres: desafios para as políticas públicas (pp. 55-64). São Paulo: Coordenadoria Especial da Mulher da Prefeitura Municipal de São Paulo.

Lameirão, A. P. (2011). Mercado de trabalho, desigualdade social e de gênero. Anais do Seminário Nacional da Pós-Graduação em Ciências Sociais, UFES, 1(1). https://periodicos.ufes.br/snpgcs/article/view/1630

Lopes, K. S., Myrrha, L. J. D., \& Queiroz, S. N. (2019, novembro). Diferenciais de gênero na composição da renda no Seridó Potiguar. Anais do Encontro Nacional sobre População, Trabalho, Gênero e Políticas Públicas, ABEP, Campinas.

Marri, I. G. (2009). Reforma da Previdência Social: simulações e impactos sobre os diferenciais de gênero, 2009. (Tese de Doutorado em Demografia). Centro de Desenvolvimento e Planejamento Regional, Faculdade de Ciências Econômicas, Universidade Federal de Minas Gerais, Belo Horizonte. https://www.cedeplar.ufmg.br/publicacoes/teses-edissertacoes/teses-demografia/category/130-2009?download=897: izabel-guimaraes-marri 
Medeiros, M., \& Pinheiro, L. S. (2018). Desigualdades de gênero em tempo de trabalho pago e não pago no Brasil, 2013. Sociedade e Estado, 33(1), 161-187. https://periodicos.unb.br/index.php/sociedade/article/view/18356

Neves, M. de A., \& Pedrosa, C. M. (2007). Gênero, flexibilidade e precarização: o trabalho a domicílio na indústria de confecções. Sociedade e Estado, 22(1), p. 11-34. https://doi.org/10.1590/S0102-69922007000100002

Oliveira, A. M. H. C. (2003). A segregação ocupacional por gênero e seus efeitos sobre os salários no Brasil. In S. Wajnman, \& A. F. Machado (Orgs.), Mercado de trabalho: uma análise a partir das pesquisas domiciliares no Brasil (pp. 121-149). Belo Horizonte: Editora UFMG.

Organização Internacional do Trabalho (OIT). (2018). Perspectivas sociales y del empleo en el mundo: Avance global sobre las tendencias del empleo feminino. Ginebra: Oficina Internacional del Trabajo. https://www.ilo.org/global/research/global-reports/weso/trendsfor-women2018/WCMS 619603/lang--es/index.htm

Rodríguez, M., \& García, B. (2020). Un modelo espacial de desigualdad de género sobre trabajo no remunerado en México. Realidad, Datos y Espacio - Revista Internacional de Estadística y Geografía, 11(1), 68-85. https://rde.inegi.org.mx/wpcontent/uploads/2020/02/RDE30.pdf http://www.alapop.org/Congreso2018/PDF/00317.pdf

Saffioti, H. (1969/2013). A mulher na sociedade de classes: Mito e realidade. (3a ed.). São Paulo: Expressão Popular.

Teixeira, M. O. (2014). Formalização do emprego e permanência das desigualdades de gênero. [Análise, dez.2014], Friedrich Ebert Stiftung (FES) Brasil, São Paulo. http://library.fes.de/pdf-files/bueros/brasilien/11198.pdf

Wajnman, S. (2006). Mulheres na sociedade e no mercado de trabalho brasileiro: avanços e entraves. In M. Porto (Org.), Olhares femininos, mulheres brasileiras (pp. 77-108). Rio de Janeiro: X Brasil.

Recebido em 05 de fevereiro de 2021. Aprovado em 30 de abril de 2021. 